\title{
Domestic airport passenger access mode choice decisions in a multi-airport region of South Africa
}

\author{
Author: \\ Stephen Carstens ${ }^{1,2}$ \\ Affiliations: \\ ${ }^{1}$ Institute of Transport and \\ Logistics Studies (Africa), \\ University of Johannesburg, \\ South Africa \\ ${ }^{2}$ Department of Transport \\ and Supply Chain \\ Management, University of \\ Johannesburg, South Africa \\ Correspondence to: \\ Stephen Carstens \\ Email: \\ stephcar@global.co.za \\ Postal address: \\ PO Box 84366, Greenside \\ 2034, South Africa \\ Dates: \\ Received: 19 June 2014 \\ Accepted: 19 Aug. 2014 \\ Published: 01 Dec. 2014 \\ How to cite this article: \\ Carstens, S., 2014, 'Domestic \\ airport passenger access \\ mode choice decisions in \\ a multi-airport region of \\ South Africa', Journal of \\ Transport and Supply Chain \\ Management 8(1), Art. \\ \#149, 7 pages. http://dx.doi. \\ org/10.4102/jtscm.v8i1.149

\section{Copyright:} \\ C 2014. The Authors. \\ Licensee: AOSIS \\ OpenJournals. This work is \\ licensed under the Creative \\ Commons Attribution \\ License.
}

\section{Read online:}

The ground access mode used by air passengers to an airport has a vital impact on infrastructural and environmental decisions. An important aspect of a passenger's mode choice is the sensitivity to factors such as access time and access cost. The objective of this research was to analyse air passenger's sensitivity to access mode choice attributes, that is, access time, access cost, parking time and parking cost at two airports in Johannesburg, South Africa. A stated choice experiment was used to obtain the information and a latent class model was estimated. In general, discrete choice experiments are designed to reveal respondent (preference) heterogeneity and the latent class model allows for this heterogeneity to be modelled discretely. The estimated results indicated that three latent classes provided the best fit with preference heterogeneity evident from the set of parameter estimates. The access mode used was found to be the only significant covariate in the class assignment model. The respondents' willingness to pay for a reduction in access time was estimated and it indicated that respondents had the highest access time willingness-to-pay value for the taxi as access mode. In addition, it was estimated that passengers being dropped off at the airport had a higher access time willingness-to-pay than passengers that used their own vehicles to the airport. The research results confirmed the presence of respondent heterogeneity (according to access mode) which resulted in different access time willingness-to-pay values.

\section{Introduction}

The ground access mode choice of passengers to an airport has a significant impact on policy decisions relating to infrastructure requirements (inclusive of airport landside planning) and the environment. Airport access modes generally include different road transport modes such as private (own) and public transport, as well as rail transport. Decision-makers find the sensitivity of passengers' airport access mode choice to external factors such as access time and access cost of great interest.

Johannesburg (Gauteng Province, South Africa) has one major international airport, Oliver R. Tambo International Airport (ORTIA) and a number of smaller regional airports, of which Lanseria International Airport (LIA) is the major competing airport in terms of domestic flights. ORTIA, which is managed by the Airports Company South Africa, provides long-haul and shorthaul services and is served by a combination of full-service scheduled carriers and low-cost carriers. LIA is privately owned and is served by charter airlines and low-cost carriers. LIA is situated approximately $35 \mathrm{~km}$ west of Johannesburg and ORTIA approximately $20 \mathrm{~km}$ east of Johannesburg.

Currently, two low-cost carriers (Kulula.com and Mango) offer domestic services from LIA to Cape Town International Airport (Western Cape Province, South Africa) and King Shaka International Airport (Durban, KwaZulu-Natal Province, South Africa). These two airlines offer similar domestic services from ORTIA. In addition, other full-cost carriers (South African Airways and British Airways Comair) also offer domestic services from ORTIA. The two airports of ORTIA and LIA have to compete for departing passengers; that is, a passenger travelling from Johannesburg (and surrounding areas) to either Cape Town or Durban has the option to depart from any one of these two airports on the 'Golden Triangle' (Luke \& Walters 2013). The Golden Triangle refers to the Johannesburg-Cape Town and Johannesburg-Durban routes (Luke \& Walters 2013). The opposite also applies, in that a passenger departing from Cape Town or Durban could choose either ORTIA or LIA as their destination. However, these airports have different characteristics in terms of services, costs, et cetera, with ORTIA being a major international airport and LIA a smaller, regional airport.

Passengers departing from these airports have various road transport options to access the airport: self-drive, drop-off, train (only applicable to ORTIA), taxi and non-scheduled bus services. Self-drive means that the passenger drives his or her vehicle to the airport and parks 
it at the airport for the trip duration. Drop-off implies that the passenger is driven to the airport by someone else and dropped off; no parking is required. The train and taxi modes are self-explanatory; although, it should be noted that the train alternative usually also involves a road transport section and is only available to ORTIA. The train service to ORTIA consists of a west-east link between the Sandton station (in the north of Johannesburg) and the airport, with an approximate $15 \mathrm{~min}$ transfer time.

These access modes have different characteristics related to costs (access and parking) and time which could influence a passenger's access mode decision. For example, travel time, travel cost and travel time reliability were found to influence the passenger's access mode choice (Nam, Park \& Khamkongkhun 2005; Tam, Lam \& Lo 2011). The access mode chosen by airport passengers is significant given the number of passengers using the airports. For example, a total of 4.6 million passengers departed from ORTIA during 2013 (Airports Company South Africa 2014).

The objective of this research is to determine the sensitivity of airport passenger access mode choice (at ORTIA and LIA) to attributes such as access time, access cost, parking time and parking cost, under the assumption of preference heterogeneity. An access time willingness-to-pay (WTP) measure was used to quantify the sensitivity to access time saving of each access mode; that is, how much a passenger is willing to pay for a reduction in travel time to the airport, given the access mode of choice. This research focuses on passengers departing on a domestic trip. For the purposes of this research, the taxi and the non-scheduled bus access modes were grouped together.

\section{Literature review}

Numerous studies focusing on the passenger's access mode choice have been published (Gaonkar 2013; Gupta, Vovsha \& Donnelly 2008; Mamdoohi et al. 2012; Tam et al. 2011). Tam et al. (2011) used a stated preference approach to establish air passengers' access mode choice sensitivity to attributes such as travel time, travel cost and travel reliability (measured in terms of the frequency of being late) at Hong Kong International Airport. The results indicated that travel cost and travel time reliability were the most important factors considered by passengers when selecting an access mode. Jevons, Hoe and Shepherd (2011) investigated air passengers' access mode choice in terms of six alternatives to Heathrow Airport, London, based on attributes such as access time, access cost, waiting time, and egress time. Although their research was aimed at establishing the attributes that have a significant influence on passengers' access mode choice, another objective of this research was to estimate time and cost elasticities based on different demographic subgroups (Jevons et al. 2011).

Other studies have been carried out to model a passenger's airport choice in a multi-airport region based on different attributes (De Luca 2012; Hess 2010; Hess \& Polak 2006; Ishii,
Jun \& Van Dender 2009; Lian \& Rønnevik 2011; Loo 2008; Pels, Nijkamp \& Rietveld 2003). Although the objectives of these studies varied and were not specifically related to the access mode choice, the stated preference models included access mode attributes such as access time and access cost. For example, Pels et al. (2003) found that business passengers in the San Francisco Bay area were more sensitive to travel time, which then was also a determining factor in the competition between airports. Hess (2010) established that although passengers included complementary information to the information presented to them when making an airport choice, travel time from the airport significantly influenced the passengers' airport choice.

\section{Research method and design Design}

It is clear from the literature that access time and access cost are important factors in the passenger's access mode choice and that the discrete choice modelling approach is suitable to model the passenger's access mode choice. Furthermore, most of this research focused on the impact of demographic information such as trip purpose (business, leisure, etc.) and income levels on the passenger's access mode choice. However, this research's main focus was the estimation of a discrete choice model based on utilities linked to the ground access modes and the estimation of access time WTP measures for the different airport access modes to ORTIA and LIA in Johannesburg.

An individual makes decisions by comparing alternatives and selecting an action, but these decisions are subject to variability (heterogeneity) and in order to model decisionmaking this variability needs to be explained (Hensher, Rose \& Greene 2005). One approach to model decision-making is through discrete choice modelling, based on random utility theory (Hensher et al. 2005). The preferences of the decisionmaker can be expressed in terms of a utility function (Hensher et al. 2005):

$U_{\mathrm{i}}=V_{\mathrm{i}}+\varepsilon_{\mathrm{i}}$

[Eqn 1]

where $U_{\mathrm{i}}=$ the utility associated with alternative $\mathrm{i}, V_{\mathrm{i}}=$ utility of alternative $i$ that can be observed and $\varepsilon_{\mathrm{i}}=$ unobserved component of alternative $i$.

There are two types of choice data: revealed preference and stated preference (Hensher et al. 2005). The revealed preference approach to discrete choice modelling focuses on the current market ('real' situations), whilst the stated preference approach allows for attribute levels that are not restricted to the current market (hypothetical situations) (Hensher et al. 2005). For the purposes of this research a stated choice experimental approach was used, which involves observing the effect of manipulating the levels of one or more variables on a response variable (Hensher et al. 2005). The manipulation of the variables occurs according to a statistical experimental design (Hensher et al. 2005). Hess, 
Adler and Polak (2007) confirmed the benefits of modelling airport choice with stated preference data.

The purpose of this research was to estimate how a number of pre-determined attributes influence the decision-making process of domestic passengers at ORTIA and LIA relating to ground access mode (i.e. estimating the departing passenger's sensitivity to access mode choice). The research involved survey results obtained from an original study on domestic departing passenger airport choice decisions in a multi-airport region - ORTIA and LIA in Johannesburg.

According to De Luca and Di Pace (2012), many of the estimated airport choice models provide for a broad understanding of airport choice without taking different choice dimensions into consideration. To this end, the original research objective (airport choice in a multi-airport region) was based on a multidimensional choice approach by including the passenger's access mode. The resultant stated preference model included seven alternatives relating to a combination of the airport (ORTIA and LIA) and mode of access (self-drive, drop-off, train, taxi).

Although the utilities related to airport access mode combinations, the mode choice utilities could be estimated separately through a different model specification, that is, alternative specific versus generic parameters. Such a parameter specification allows for the estimation of sets of parameter estimates for self-drive, drop-off, train and taxi as potential ground access modes, irrespective of airport choice. The estimated model included seven alternatives with generic parameter specifications for the airline attributes (airline, air fare, flight delay and flight frequency), as well as for the access time and access cost related to the different modes of access (i.e. self-drive, drop-off, train and taxi). In addition, generic parameters were specified for parking time and parking cost, related to the self-drive access mode.

Bliemer and Rose (2011) emphasised the importance of the choice of experimental design on the reliability of parameter estimates and concluded that efficient designs result in more reliable parameter estimates. A Bayesian, D-optimal efficient (balanced) design with 60 choice sets was generated with Ngene 1.1.1 (Bliemer, Rose \& Hess 2006). The overall design was blocked into 6 subsets, with 10 choice sets each. The $a$ priori distributions for the parameters were estimated from a pilot survey.

Rose et al. (2008) illustrated that to increase the reliability of the parameter estimates further, efficient designs can be generated by using the respondent's reference (or status quo) alternative as base for the attribute levels. Hess (2008) also confirmed that in an effort to improve response quality, researchers should use the respondent's real trip to frame the choice situations.

The experimental design for this research was partially based on the respondent's reference; that is, the different
TABLE 1: Description of the stated choice experiment levels.

\begin{tabular}{ll}
\hline Attribute & Levels \\
\hline Access time - ORTIA (West) & $-15 \mathrm{~min}$, Reference, $+15 \mathrm{~min}$ \\
Access time - ORTIA (East) & $-5 \mathrm{~min}$, Reference, $+5 \mathrm{~min}$ \\
Access time - LIA (West) & $-5 \mathrm{~min}$, Reference, $+5 \mathrm{~min}$ \\
Access time - LIA (East) & $-15 \mathrm{~min}$, Reference, $+15 \mathrm{~min}$ \\
Access cost & $-20 \%,-10 \%$, Reference, $+10 \%,+20 \%$ \\
Parking time - ORTIA & $10 \mathrm{~min}, 15 \mathrm{~min}, 20 \mathrm{~min}$ \\
Parking time - LIA & $5 \mathrm{~min}, 10 \mathrm{~min}, 15 \mathrm{~min}$ \\
\hline Parking cost & $-20 \%,-10 \%$, Reference, $+10 \%,+20 \%$ \\
\hline
\end{tabular}

ORTIA, O.R. Tambo International Airport; LIA, Lanseria International Airport.

levels of certain attributes were varied (pivoted) based on the passenger's current experience (Hess 2008). Access time, access cost and parking costs were pivoted on the respondent's reference and the parking time had fixed levels (Table 1). The reference information was obtained at the start of the survey and the subsequent games were based on the percentage changes as per the experimental design (Table 1).

\section{Procedure}

The access time levels varied according to the respondent's trip departure point (geographical location), based on the distance from each of the airports. This was done to maintain a level of realism of the access times. Thus, a total of 312 departing domestic passengers at ORTIA and 306 departing domestic passengers at LIA were surveyed, with each passenger completing 10 choice situations, resulting in 6180 records. The survey instrument was a computer-aided personal interview, which was completed at the airport prior to the respondent boarding the aircraft. The samples of passengers at both airports were approximately equally representative of the day of the week, airlines, departure times and destinations (Durban and Cape Town).

Although the basic multinomial logit model has been used extensively in the past, the model's assumption of independence from irrelevant alternatives, which is very restrictive, has resulted in research into approaches that relax this assumption (Greene \& Hensher 2003). The independence from irrelevant alternatives assumption implies that 'the ratio of the choice probabilities of any pair of alternatives is independent of the presence or absence of any other alternative in a choice set' (Hensher et al. 2005:479). One approach to allow for respondent variation is the latent class model (Greene \& Hensher 2003). This model allows for preference heterogeneity to occur discretely according to a number of latent classes (Ortega et al. 2011). Unlike the mixed multinomial logit model, where the parameter distributions have to be specified a priori, the latent classes are established from the data. Furthermore, the probability that a respondent belongs to a latent class may be linked to covariates such as purpose of travel, age, gender, access mode, et cetera. This provides some information in terms of the make-up of the different classes (De Bekker-Grob et al. 2013). For this research a panel latent class model was used, as each respondent was required to complete 10 choice tasks. 
The choice probability that respondent $i$ of class $q$ selects alternative $j$ from a set $J$ in $\mathrm{T}_{i}$ choice situations can be expressed as (Greene \& Hensher 2003):

$P_{\mathrm{it} / \mathrm{q}}(j)=\frac{\exp \left(\beta_{\mathrm{q}}{ }^{\prime} X_{\mathrm{it}, \mathrm{j}}\right)}{\sum_{\mathrm{j}=1}^{\mathrm{j}} \exp \left(\beta_{\mathrm{q}}{ }^{\prime} X_{\mathrm{it}, \mathrm{j}}\right)}$

where $\beta_{\mathrm{q}}^{\prime}$ is the parameter vector associated with the vector of explanatory variables $X_{\mathrm{it}, \mathrm{j}}$ associated with alternative $j$. The latent class model simultaneously estimates these probabilities for $S$ classes and the probability of individual $i$ being in class $q\left(H_{\mathrm{iq}}\right)$. Therefore, the unconditional probability of choosing alternative $i$ is (Greene \& Hensher 2003):

$P_{\mathrm{i}}=\sum_{\mathrm{q}=1}^{\mathrm{Q}} P_{\mathrm{it} / \mathrm{q}} H_{\mathrm{iq}}$

The class assignment $H_{\mathrm{iq}}$ is unknown, but may be modelled through a multinomial logit model, as follows (Greene \& Hensher 2003):

$H_{\mathrm{iq}}=\frac{\exp \left(\theta_{\mathrm{s}}{ }^{\prime} z_{\mathrm{i}}\right)}{\sum_{\mathrm{q}=1}^{\mathrm{J}} \exp \left(\theta_{\mathrm{s}}{ }^{\prime} z_{\mathrm{i}}\right)}$

where $z_{\mathrm{i}}$ represents a set of observable characteristics that enter the model for class membership.

The class parameter estimates indicate that, conditional to belonging to that class, the respondents view the attributes important in making a decision, provided that the coefficient is statistically significant ( $p$-value $\leq 0.05$ ). Based on significant parameter estimates, an access time WTP value may be calculated for each class, as follows (De Bekker-Grob et al. 2013):

$W T P_{\mathrm{q}}=\frac{\beta_{\text {time/q }}}{\beta_{\text {cost } / \mathrm{q}}}$

However, the class WTP values are of little value because the latent class model assumes that each respondent belongs to all classes up to a probability (De Bekker-Grob et al. 2013). However, it is possible to calculate an overall (mean) WTP value by using the probability that a respondent belongs to a class as weight for the conditional WTP value, as follows (De Bekker-Grob et al. 2013):

$W T P=\sum_{\mathrm{q}}^{\mathrm{Q}} P_{\mathrm{q}} \frac{\beta_{\text {time/q }}}{\beta_{\text {cost/q }}}$

[Eqn 6]

A latent class model was assumed and the parameters estimated with Nlogit version 5 on the combined dataset (ORTIA and LIA). Greene and Hensher (2003), as well as Shen, Sakata and Hashimoto (2006) have concluded that the latent class model performs statistically better than other models on specific datasets in the presence of respondent choice heterogeneity. However, this may depend on the sample.

\section{Results}

A total of 618 departing domestic passengers were surveyed (two airports combined), with each passenger completing 10 choice situations, resulting in 6180 records. The sample composition is depicted in Table 2.

The majority of the respondents used the two low-cost airlines (Kulula.com and Mango), travelled for business purposes and used the drop-off alternative as airport access mode. The sample composition indicates that road transport (self-drive, drop-off and taxi) accounted for the largest proportion of access modes used. This is mainly because the train was only an option for passengers travelling to ORTIA and required the passenger to either drive to the train station themselves and park the vehicle, use the drop-off option or use the bus service to the train station.

The Nlogit version 5 estimation results indicate that a latent class model with three classes provided the 'best' fit based on log-likelihood, Akaike information criterion and the McFadden pseudo $R^{2}$, as shown in Table 3. The average class probabilities were $49.0 \%, 29.2 \%$ and $21.8 \%$ for latent Class 1 , 2 , and 3 , respectively. The probability of belonging to a class depended mainly on the respondent's access mode for the trip: self-drive, drop-off, train and taxi (travel). The high level of statistical significance of this coefficient indicates that the access mode had a significant impact on the respondent's evaluation of the choice attributes. Although other covariates (gender, age, purpose of travel and the region where the trip originated from) were used, they were not included in the final model because of statistical insignificance and poor model fit. Low levels of correlation were recorded between the covariates utilised for the class assignment model: travel (access mode), purpose of travel (business, leisure, etc.), age and gender.

\section{Discussion}

The class assignment model indicates that Class 1 represented respondents that were more likely to get dropped off at the airport or use the train as the mode of airport access. Class 2 respondents were more likely to use their own transport (i.e. use the self-drive option) to access the airport compared

TABLE 2: Sample composition of respondents.

\begin{tabular}{lll}
\hline Variable & Composition & $\mathbf{\%}$ \\
\hline Airline & Kulula.com & 36 \\
& Mango & 36 \\
& South African Airways & 15 \\
Access mode & British Airways Comair & 13 \\
& Self-drive & 31 \\
& Drop-off & 56 \\
Gender & Train & 10 \\
& Taxi & 4 \\
Purpose of travel & Male & 60 \\
& Female & 40 \\
& Business & 53 \\
& Leisure & 17 \\
& Visiting friends and relatives & 23 \\
& Sports & 2 \\
\hline
\end{tabular}


TABLE 3: Nlogit estimation results based on respondents' preferences.

\begin{tabular}{|c|c|c|c|c|c|c|c|c|}
\hline \multirow[t]{2}{*}{ Parameters } & \multicolumn{8}{|c|}{ Coefficient } \\
\hline & Multinomial logit & $p$-value & Class 1 & $p$-value & Class 2 & $p$-value & Class 3 & $p$-value \\
\hline$\overline{\mathrm{O} 1}$ & $1.87689 * * *$ & 0.0014 & -6.57129 & 1.0000 & 1.13666 & 0.9626 & $-2.75374 *$ & 0.0794 \\
\hline AIR & 0.01603 & 0.5008 & 0.02175 & 0.6209 & 0.05428 & 0.2794 & -0.07266 & 0.4077 \\
\hline FARE & $-0.00117 * * *$ & 0.0000 & $-0.00170 * * *$ & 0.0000 & $-0.00165^{* * *}$ & 0.0000 & $-0.00111 * * *$ & 0.0000 \\
\hline DELAY & $-0.00695 * * *$ & 0.0000 & $-0.00771 * * *$ & 0.0000 & $-0.02001 * * *$ & 0.0000 & -0.00115 & 0.7532 \\
\hline FREQ & $0.11111 * * *$ & 0.0000 & $0.17130 * * *$ & 0.0001 & $0.12792 * *$ & 0.0130 & 0.05249 & 0.5678 \\
\hline SATIME & $-0.01412 * * *$ & 0.0020 & -0.03642 & 0.4390 & $-0.01085 * * *$ & 0.0000 & $-0.07687 * * *$ & 0.0011 \\
\hline SPTIME & $0.01786 * * *$ & 0.0055 & -0.03389 & 0.6266 & 0.01969 & 0.1913 & -0.03079 & 0.7355 \\
\hline SACOST & $-0.00872 * * *$ & 0.0000 & -0.00475 & 0.5142 & $-0.01074 * * *$ & 0.0000 & $0.01447 * * *$ & 0.0000 \\
\hline SPCOST & $-0.00210 * * *$ & 0.0000 & $-0.00273 * *$ & 0.0354 & $0.00054 * *$ & 0.0259 & $-0.00347 * * *$ & 0.0030 \\
\hline $\mathrm{O} 2$ & $2.85248 * * *$ & 0.0000 & -1.77613 & 1.0000 & -3.80498 & 0.8748 & $1.32675 * *$ & 0.0422 \\
\hline DATIME & $-0.02860 * * *$ & 0.0000 & $-0.03893 * * *$ & 0.0000 & 0.00579 & 0.8830 & $-0.05622 * * *$ & 0.0001 \\
\hline DACOST & $-0.00627 * * *$ & 0.0000 & $-0.00684 * * *$ & 0.0000 & -0.00328 & 0.3979 & $-0.00812 * * *$ & 0.0000 \\
\hline $\mathrm{O} 3$ & $1.13306^{*}$ & 0.0640 & -5.20964 & 1.0000 & -0.84728 & 0.9719 & $1.60365 * *$ & 0.0459 \\
\hline TACOST & $.85847 \mathrm{D}-04$ & 0.9611 & $-0.01237^{*}$ & 0.0795 & -0.01811 & 0.1712 & -0.00511 & 0.2384 \\
\hline $\mathrm{O} 4$ & $-0.40697 * *$ & 0.0266 & 14.3421 & 1.0000 & -8.65992 & 0.9992 & -0.09208 & 0.6252 \\
\hline TAATIM & $-0.02952 * * *$ & 0.0004 & 0.11126 & 0.6750 & -0.10297 & 0.6995 & $-0.01587^{*}$ & 0.0678 \\
\hline TAACOS & $-0.00374 * *$ & 0.0100 & -0.09419 & 0.5983 & -0.00559 & 0.9497 & $-0.00394 * *$ & 0.0142 \\
\hline L1 & $2.30477 * * *$ & 0.0001 & -5.67821 & 1.0000 & 1.48298 & 0.9512 & -1.35125 & 0.2864 \\
\hline L2 & $3.29278 * * *$ & 0.0000 & -1.05078 & 1.0000 & -3.40836 & 0.8878 & $1.85310 * * *$ & 0.0086 \\
\hline Class probability & - & - & 0.490 & - & 0.292 & - & 0.218 & - \\
\hline Class assignment model: Constant & - & - & $5.44875 * * *$ & 0.0000 & $11.8473 * * *$ & 0.0000 & 0.0000 & 0.0000 \\
\hline Class assignment model: Travel & - & - & $-2.07682 * * *$ & 0.0000 & $-6.58093 * * *$ & 0.0000 & 0.0000 & 0.0000 \\
\hline Log-likelihood function & - & -9188.0731 & - & - & -4491.24702 & - & - & - \\
\hline Akaike information criterion & - & 2.98 & - & - & 1.474 & - & - & - \\
\hline McFadden pseudo $R^{2}$ & - & 0.105207411 & - & - & 0.62653 & - & - & - \\
\hline
\end{tabular}

AIR, airline; FARE, fare; DELAY, flight delay; FREQ, frequency of flights; SATIME, access time self-drive; SPTIME, parking time self-drive; SACOST, access cost self-drive; SPCOST, parking cost self-drive; DATIME, access time drop-off; DACOST, access cost drop-off; TATIME, access time train; TACOST, access cost train; TAATIM, access time taxi; TAACOS, access cost taxi; O1, O2, O3, L1, L2 = constants. $* * *, * *, *$ Significance at $1 \%, 5 \%, 10 \%$ level.

to Class 3. Class 3 respondents were more likely to represent passengers using mainly the train or taxi modes of access.

The access mode related parameter estimates for each latent class in general had the correct sign and were significant in terms of the class assignment model. The negative signs for both the access time and access cost parameter estimates indicate that passengers preferred shorter access times at a lower cost. A better fit was obtained by including attributes relating to the trip itself: the airline, fare, departure delays and the frequency of departing flights. The results indicate that the airline (AIR) did not significantly influence the passenger's choice, but the fare (FARE) was significant for all classes. Both delays in departure time (DELAY) and flight frequency (FREQ) were significant for both Class 1 and Class 2, but not for Class 3 .

The Class 1 access mode parameter estimates indicate that the access time and access cost of the drop-off (DATIME and DACOST) and train (TATIME and TACOST) options were significant. In addition, the parking cost parameter estimate (SPCOST) was significant with a negative sign, indicating that these passengers would prefer to pay less for parking if they would have used their own vehicles to get to the airport (self-drive).

The significant access mode parameter estimates in Class 2 were access time and access cost associated with self-drive (SATIME and SACOST), as well as parking cost (SPCOST). The parking cost parameter estimate was positive, indicating that these passengers were prepared to pay more for parking. However, passengers in this class mainly used the self-drive access option according to the class assignment model and parking was a necessity, which could be indicative of a parking shortage at the airports.

The significant access mode parameter estimates in Class 3 related to parking cost (SPCOST), the access time and access cost of the self-drive (SATIME and SACOST), dropoff (DATIME and DACOST) and the taxi (TAATIM and TAACOS) alternatives. The positive sign of the access cost parameter associated with the self-drive option indicates that respondents in this class (respondents belonging to this class were more likely to be using mainly the taxi modes of access) were prepared to pay more for using their own vehicle to access the airport.

The results indicate that the access time and access cost of each access mode significantly influenced the passenger's choice depending on the latent class, as expected. However, the preference heterogeneity was clearly visible, as illustrated by the difference in parameter values between classes.

Although it is possible to calculate access time WTP measures relating to each access mode for each class, De Bekker-Grob et al. (2013) indicate that an overall (mean) (probability weighted) WTP for each access mode would be of more value. An additional problem with the calculation of class-specific WTP measures is that the estimated time or cost parameters 
TABLE 4: Access time willingness-to-pay of respondents.

\begin{tabular}{llll}
\hline Access mode & WTP (Rand per hour) & \multicolumn{2}{c}{ Confidence interval } \\
\cline { 3 - 4 } & & Lower & Upper \\
\hline Self-drive & 172.45 & -438.27 & 787.21 \\
Drop-off & 226.77 & -195.74 & 649.28 \\
Train & 106.18 & -30.72 & 243.09 \\
Taxi & 339.38 & -655.56 & 1334.31 \\
\hline
\end{tabular}

WTP, willingness to pay.

may not be significant in certain classes. For example, in Class 1 the access time and access cost parameters associated with the self-drive option were not significant, implying that calculating a WTP measure for this specific access mode in this class is meaningless.

Table 4 shows the overall (mean) WTP measures relating to access time of each of the ground access modes, as well as the $95 \%$ confidence intervals. Nlogit version 5 estimates individual specific WTP values based on individual specific parameter estimates that are probability weighted over the classes. The WTP values displayed in Table 4 are the mean WTP measures calculated from the individual specific WTP values. The confidence intervals (95\%) were approximated by treating the WTP as a mean of a variable. This implies that the class probability errors were not accounted for in the calculation of the confidence intervals.

The calculated WTP measures further indicate levels of preference heterogeneity present in the sample. Passengers using the drop-off alternative were prepared to pay more, on average, to save time than passengers using their own transport (self-drive). This could be because the self-drive alternative implies only a one-way trip to the airport, whereas the drop-off alternative implies a round trip to the airport, rendering a time saving more important. The results indicate that passengers using the self-drive, drop-off and taxi modes of access had a higher WTP value compared to the public transport option (train). This is in accordance with the findings of Tsamboulas and Nikoleris (2008), although a different approach was used in their study. However, care should be taken with comparing these results to the results of studies completed elsewhere, as the results of a discrete choice experiment are specific to the choice environment and transferability could be compromised. The wide range of the confidence intervals indicate considerable differences in access time WTP values, which is indicative of preference heterogeneity.

\section{Conclusion}

An airport passenger's choice of access mode is important in terms of infrastructure development and planning. Airport access modes in general include a combination of private transport and public transport, that is, road transport (selfdrive, drop-off, taxi and bus) and train. The extent to which a passenger's mode choice is influenced by mode attributes (access time, access cost) could play an important role in future infrastructure planning and development.

The aim of this research was to investigate the sensitivity of passengers using different modes of airport access to transport specific attributes such as access time, access cost, parking time and parking cost. In addition, an access time WTP value was calculated for the different ground access modes. The research focused on passengers departing on a domestic flight at the two airports in Johannesburg, ORTIA and LIA.

Research has indicated that the influence of mode attributes on mode choice may be estimated through the use of a discrete choice modelling approach, specifically a stated choice experiment which is not bounded to existing attribute levels. The stated choice approach allows the researcher to investigate attribute levels that do not currently exist. Research into airport passengers' choices found that access time and access cost have a significant influence on the passengers' airport choice decision. This research was based on a stated choice experiment that allowed for the estimation of access mode specific parameters. Respondents were surveyed prior to departing from the two airports in Johannesburg and the attribute levels of certain attributes were pivoted on the respondent's current access trip experience.

Recent advances in discrete choice modelling have focused on relaxing the independence from irrelevant alternatives assumption of the multinomial logit model, allowing for respondent preference heterogeneity. One approach to allow for preference heterogeneity is the latent class model, which models the heterogeneity discretely according to different classes. The estimation results indicated three classes with the respondent's current access mode as significant parameters of the class assignment model; that is, the access mode used by the respondent for the current trip was found to be significant in the class assignment model. The class assignment model was estimated as follows (class probabilities in brackets):

- Class 1: More likely to consist of respondents using the drop-off and train as access modes (49.0\%).

- Class 2: More likely to consist of respondents using self-drive as access mode (29.2\%).

- Class 3: More likely to consist of respondents using the train or a taxi as access mode $(21.8 \%)$.

The significant access mode parameter estimates (access time, access cost, parking time and parking cost) varied by class, which is an indication of preference heterogeneity and is also indicated by the wide WTP confidence intervals.

The research results indicated that respondents had the highest WTP for the taxi mode of access (R339 per h), which could be a result of the fact that taxi fares are linked to travel time. The lowest WTP was calculated for the train alternative (R106 per h), which may be attributed to the fact that the train option involves fixed schedules and a short transfer time with little opportunity of time savings. The estimated WTP for the drop-off alternative (R227 per h) was higher than that of the self-drive alternative (R172 per h), which could be attributed to the fact that the former access mode involves a round trip to the airport rendering travel time savings more important. These results are specific to the 
experimental choice environment in Johannesburg, that is, access to two airports for the purposes of domestic travel via road transport and rail transport to only one airport.

Road transport is the dominant airport access mode in Johannesburg and a portion of the access time relates to access at the airports, in terms of access to the parking areas and access to the drop-off zones. The airports specifically need to ensure that the access to the drop-off zones is time-efficient because the two access modes with the highest estimated WTP measures utilise the drop-off zones at the airport.

This research was completed prior to the implementation of an e-toll system on the major freeways in Gauteng, which many passengers may have used to access the airports. This may affect the passengers' access mode choice, as well as the associated WTP values.

\section{Acknowledgements \\ Competing interests}

The author declares that he has no financial or personal relationships that may have inappropriately influenced him in writing this article.

\section{References}

Airports Company South Africa, 2014, Departure passengers, viewed 22 April 2014, from http://www.airports.co.za/uploads/PassengerStatistics/ORTAMBO_ Departure_PassengerFebruary2014.pdf

Bliemer, M.C.J. \& Rose, J.M., 2011, 'Experimental design influences on stated choice outputs: An empirical study in air travel choice', Transportation Research Part A 45, 63-79. http://dx.doi.org/10.1016/j.tra.2010.09.003

Bliemer, M.C.J., Rose, J.M. \& Hess, S., 2006, Approximation of Bayesian efficiency in experimental choice designs, Institute of Transport and Logistics Studies, The University of Sydney.

De Bekker-Grob, E.W., Rose, J.M., Donkers, B., Essink-Bot, M-L., Bangma, C.H. \& Steyerberg, E.W., 2013, 'Men's preferences for prostate cancer screening: A discrete choice experiment', British Journal of Cancer 108, 533-541. http:// dx.doi.org/10.1038/bjc. 2013.5

De Luca, S., 2012, 'Modelling airport choice behaviour for direct flights, connecting flights and different plans', Journal of Transport Geography 22, 148-163. http:// dx.doi.org/10.1016/j.jtrangeo.2011.12.006

De Luca, S. \& Di Pace, R., 2012, 'Modelling passenger departure airport choice: Implicit vs. explicit approaches', 15th Edition of the Euro Working Group on Transportation, Paris, France, 10-13 September 2012

Gaonkar, P.D., 2013, 'Analysis of airport ground accessibility in India by explicating the case of CSI Airport, Mumbai', International Journal of Scientific and Research Publications 3(7), 1-7.

Greene, W.H. \& Hensher, D.A., 2003, 'A latent class model for discrete choice analysis: Contrasts with mixed logit', Transportation Research Part B 37, 681-698. http:// dx.doi.org/10.1016/S0191-2615(02)00046-2
Gupta, S., Vovsha, P. \& Donnelly, R.M., 2008, 'Air passenger preferences for choice of airport and ground access mode in the New York City Metropolitan region' Transportation Research Record: Journal of the Transportation Research Board 2042, 3-11. http://dx.doi.org/10.3141/2042-01

Hensher, D.A., Rose, J.M. \& Greene, W.H., 2005, Applied choice analysis: A primer Cambridge University Press, Cambridge.

Hess, S., 2008, 'Treatment of reference alternatives in stated choice surveys for air travel choice behaviour', Journal of Air Transport Management 14, 275-279. http://dx.doi.org/10.1016/j.jairtraman.2008.06.001

Hess, S., 2010, 'Evidence of passenger preferences for specific types of airports', Journal of Air Transport Management 16, 191-195. http://dx.doi.org/10.1016/j. jairtraman.2009.11.006

Hess, S. \& Polak, J.W., 2006, 'Exploring the potential for cross-nesting structures in airport-choice analysis: A case study of the Greater London area', Transportation Research Part E: Logistics and
org/10.1016/j.tre.2005.09.001

Hess, S., Adler, T. \& Polak, J.W., 2007, 'Modelling airport and airline choice behaviour with the use of stated preference survey data', Transportation Research Part E 43, 221-233. http://dx.doi.org/10.1016/j.tre.2006.10.002

Ishii, J., Jun, S. \& Van Dender, K., 2009, 'Air travel choices in multi-airport markets', Journal of Urban Economics 65(2), 216-227. http://dx.doi.org/10.1016/j. jue.2008.12.001

Jevons, D., Hoe, T. \& Shepherd, M., 2011, 'Understanding customer preferences for airport access: Implications for forecasting', Airport Management 5(3) 226-238

Lian, J.I. \& Rønnevik, J., 2011, 'Airport competition - Regional airports losing ground to main airports', Journal of Transport Geography 19, 85-92. http://dx.doi org/10.1016/j.jtrangeo.2009.12.004

Loo, B.P.Y., 2008, 'Passengers' airport choice within multi-airport regions (MARs): Some insights from a stated preference survey at Hong Kong International Airport', Journal of Transport Geography 16(2), 117-125. http://dx.doi.org/10.1016/j. jtrangeo.2007.05.003

Luke, R. \& Walters, J., 2013, 'Overview of the developments in the domestic airline industry in South Africa since deregulation', Journal of Transport and Supply Chain Management 7(1), Art \#117, 11 pages. http://dx.doi.org/10.4102/jtscm. Chain Mand
v7i1.117

Mamdoohi, A.R., Saffarzade, M., Tahepour, A. \& Yazdan Panah, M., 2012, 'Modeling air passengers' ground access mode choice: A case study of IKIA', International Journal of Modeling and Optimization 2(2), 147-152. http://dx.doi.org/10.7763/ JJMO.2012.V2.101

Nam, D., Park, D. \& Khamkongkhun, A., 2005, 'Estimation of value of travel time reliability', Journal of Advanced Transportation 39(1), 39-61. http://dx.doi. org/10.1002/atr.5670390105

Ortega, D.L., Wang, H.H., Wu, L. \& Olynk, N.J., 2011, 'Modeling heterogeneity in consumer preferences for select food safety attributes in China', Food Policy 36 318-324. http://dx.doi.org/10.1016/j.foodpol.2010.11.030

Pels, E., Nijkamp, P. \& Rietveld, P., 2003, 'Access to and competition between airports: A case study for the San Francisco Bay area', Transportation Research Part A 37, 71-83. http://dx.doi.org/10.1016/S0965-8564(02)00007-1

Rose, J.M., Bliemer, M.C.J., Hensher, D.A. \& Collins, A.T., 2008, 'Designing efficient stated choice experiments involving respondent based reference alternatives', Transportation Research Part B 42(4), 395-406. http://dx.doi.org/10.1016/j. trb.2007.09.002

Shen, J., Sakata, Y. \& Hashimoto, Y., 2006, 'A comparison between latent class model and mixed logit model for transport mode of choice: Evidences from two datasets Graduate School of Economics and Osaka School of International Public Policy (OSIPP), Osaka University.

Tam, M., Lam, W.H.K. \& Lo, H., 2011, 'The impact of travel time reliability and perceived service quality on airport ground access mode choice', Journal of Choice Modelling 4(2), 49-69. http://dx.doi.org/10.1016/S17555345(13)70057-5

Tsamboulas, D.A. \& Nikoleris, A., 2008, 'Passengers' willingness to pay for airport ground access time savings', Transportation Research Part A 42, 1274-1282. http://dx.doi.org/10.1016/j.tra.2008.03.013 